SURFACE AREA, VOLUME, MASS, AND DENSITY DISTRIBUTIONS FOR SIZED BIOMASS PARTICLES

FOURTH SEMI-ANNUAL PROGRESS REPORT

REPORTING PERIOD START DATE： JANUARY 01, 2006

REPORTING PERIOD END DATE: JUNE 30, 2006

PRINCIPAL AUTHOR: $\quad$ RAMANATHAN SAMPATH, PH.D

DATE REPORT WAS ISSUED: JULY, 2006

GRANT NUMBER: $\quad$ DE-FC26-04NT42130

NAME AND ADDRESS OF SUBMITTING ORGANIZATION:

DEPARTMENT OF PHYSICS AND DUAL DEGREE ENGINEERING MOREHOUSE COLLEGE

ATLANTA, GA 30314 


\section{DISCLAIMER}

This report was prepared as an account of work sponsored by an agency of the United States Government. Neither the United States Government nor any agency thereof, nor any of their employees, makes any warranty, express or implied, or assumes any legal liability or responsibility for the accuracy, completeness, or usefulness of any information, apparatus, product, or process disclosed, or represents that its use would not fringe privately owned rights. Reference herein to any specific commercial product, process, or service by trade name, trademark, manufacturers, or otherwise does not necessarily constitute or imply its endorsement, recommendation, or favoring by the United States Government or any agency thereof. The views and opinions of authors expressed herein do not necessarily state or reflect those of the United States Government or any agency thereof. 


\title{
Surface Area, Volume, Mass, and Density Distributions for Sized Biomass Particles
}

\begin{abstract}
This semi-annual technical progress report describes work performed at Morehouse College under DOE Grant No. DE-FC26-04NT42130 during the period January 01, 2006 to June 30, 2006 which covers the fourth six months of the project. Presently work is in progress to characterize surface area, volume, mass, and density distributions for sized biomass particles. During this reporting period, Morehouse completed obtaining additional mean mass measurements for biomass particles employing the gravimetric technique measurement system that was set up in a previous reporting period. Simultaneously, REM, our subcontractor, has completed obtaining raw data for surface area, volume, and drag coefficient to mass ratio $\left(\mathrm{C}_{\mathrm{d}} / \mathrm{m}\right)$ information for 9 more biomass particles employing the electrodynamic balance (EDB) measurement system that was calibrated before in this project. Results of the mean mass data obtained to date are reported here, and analysis of the raw data collected by REM is in progress.
\end{abstract}




\section{TABLE OF CONTENTS}

page

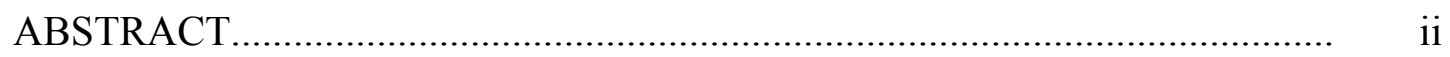

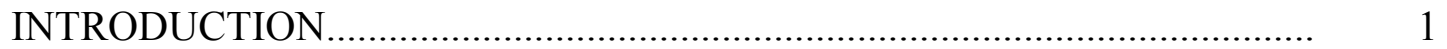

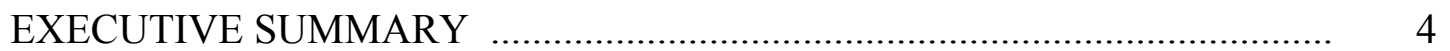

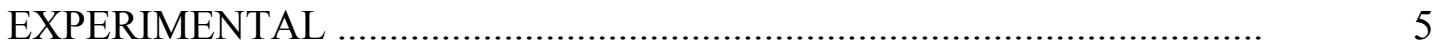

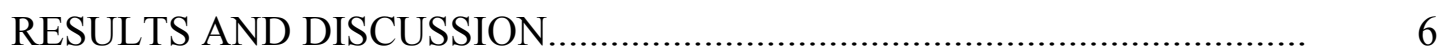

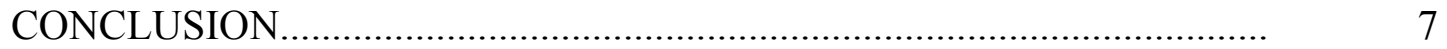

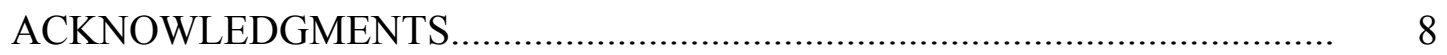

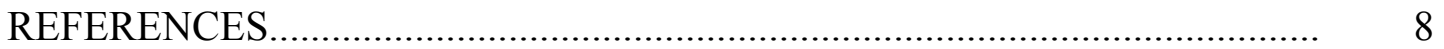




\section{INTRODUCTION}

The term biomass refers to material of terrestrial plant origin. Hardwoods, softwoods, wheat straw, corn kernel, cassava roots, sugar cane bagasse, and coconut shells are some of the largely available agricultural biomass materials. Wood is one of the most important biomass materials that could potentially be diverted to other uses. The amount of biomass produced has been estimated to be 170 billion tons per year, of which about $70 \%$ is from forests [1]. An estimate of the amount of biomass available in the U.S. for conversion to fuels or chemicals is 2 billion tons per year [2]. The conversion of $20 \%$ of this material provides an energy equivalent of $6.5 \times 1015$ BTU, roughly $10 \%$ of the U.S. annual energy needs [1].

The political (indigenous supply) and environmental (low sulfur, no net $\mathrm{CO}_{2}$, biodegradable) benefits of using biomass will continue to provide impetus to the development of co-firing coal with biomass feed stocks. Co-firing of biomass and coal has been identified as a promising way of reducing net $\mathrm{CO}_{2}$ emissions with minimum modifications in the existing technologies. In fact, some developed countries, e.g., Denmark, have already mandated the use of coal biomass blends in all coal fired boilers. Coal and biomass are certain to remain a primary source of energy for at least several decades, and this is why a great need exists to develop modern combustion systems characterized by high carbon utilization (combustion efficiency) and low emission of pollutants $\left(\mathrm{SO}_{2}, \mathrm{NO}_{\mathrm{x}}, \mathrm{N}_{2} \mathrm{O}\right.$, air toxics, etc.). One of the most important factors affecting the performance of utility boilers is fuel type. In some cases, blending biomass with coal may solve a pollution compliance problem or an operational problem or provide an economic benefit.

Coal and biomass particles are irregular in shape. Early attempts to characterize shape relied primarily on sieve analyses to classify particle "size." This approach was subsequently augmented by microscopic measurements and sizing methods based on sedimentation rates in fluids. These methods however, give no indication of the inclination of the axes of the body with respect to three coordinates, the type of geometrical shape, the volume or the surface area [3]. Heywood [4] dealt with this issue by defining shape-dependent coefficients in his analysis of volume and surface area. These coefficients are functions of the proportions of the particle, i.e., the relative values of breadth (B), thickness (T), and length (L). These are obtained by resting the particle in its most stable position. Breadth, B, is defined as the minimal distance between two parallel tangents to the profile or outline of the particle; length, L, is defined similarly but taken at right angles to the breadth; and thickness $\mathrm{T}$, is the height normal to the resting plane.

Detailed information on shape, drag, volume, density, and surface area is needed to improve our understanding of transport phenomena of irregular particles. From a fluid mechanics standpoint, a data base on various shapes of particulates would enhance the current ability to design and analyze feeder systems, cyclones, fluidized beds, and particulate separation systems. From a heat and mass transfer perspective, particle mass and shape are important considerations. In general, to simplify the analysis, heat transfer calculations are performed assuming particles to be spheres. Several studies have been published in recent years where this approach has been used and temperature measurements have been compared with model predictions [5-7]. In each of these studies, however, large empirical corrections were required in order to match model predictions with measurements. 
Maloney and coworkers [5] concluded that these corrections were necessary primarily because of the shape and density, and thermal property assumptions applied in the heat transfer analysis.

Energy absorption and emission mechanisms depend on a particle's surface area whereas its temperature response depends strongly on mass $(\rho v)$. For irregular particles such as coal, the equivalent diameters for external surface area and volume can differ significantly [8]. Moreover, the density for these particles is found to be non-uniform [8]. Hence, in-situ measurement of particle shape and density in addition to temperature measurement would allow one to better characterize and predict the thermal transport characteristics of coal particles during devolatilization and combustion. Hurt and Mitchell [9] reported large particle-to-particle temperature variations in their combustion studies of single char particles. They concluded that particle-to-particle variations in physical properties are a leading cause of these large temperature differences. Thus, individual particles have unique surface area, volume, and density and a unified approach comprising measurements of these properties is necessary if reliable predictions of transport phenomena are to be achieved.

In pursuit of this unified approach, various experimental techniques were developed recently in the single particle laboratory at the National Energy Technology Laboratory (NETL), Morgantown. These techniques involve the use of an electrodynamic balance (EDB) to characterize particle properties. The principal advantage of this instrument is the capability of suspending a charged particle motionless at the balance's geometric center, thus facilitating particle characterization.

Using a video-based imaging system, Maloney et al. [10] developed capabilities for measuring 3-D surface areas and volumes of irregular particles. Individual particles were rotated about the EDB center axis using a set of tangentially directed gas jets. As the particle rotates, a video-based imaging system records the particle images and stores perimeter data from successive video fields. Rotation rates were measured with the aid of a second video system positioned above the balance. Surface areas and volumes were calculated by summing the surface and volume elements swept out during rotation from one video field to the next.

Maloney et al. [11] also developed capabilities for measuring drag coefficient/mass ratios $\left(\mathrm{C}_{\mathrm{d}} / \mathrm{m}\right)$ for particles in the EDB. Using a high-speed diode array imaging system, they measured particle trajectories resulting from an applied stimulus. Particle $\mathrm{C}_{\mathrm{d}} / \mathrm{m}$ ratios were found from these trajectory measurements by means of a force balance model which matched theoretical predictions with measurements. Surface area and volume data were then used to estimate the particle drag coefficient by applying an analysis for deformed spheres derived by Brenner [12]. The particle mass was then calculated based on the measured $\mathrm{C}_{\mathrm{d}} / \mathrm{m}$ and the calculated drag coefficient [8].

Sampath [13] developed a second method of characterizing the volume, external surface area, and drag equivalent diameter of an irregular particle based on conventions established by Heywood [4]. This method incorporated the same EDB measurement system and associated instruments that were developed by Maloney et al. [10] to characterize irregular particles. In this method, irregular particles were characterized by obtaining directly the magnitudes of length, breadth, thickness, and 
projected areas from two view images in the planes parallel and perpendicular to the orientation of the particle during the measurement. The $\mathrm{Cd} / \mathrm{m}$ ratio was also found for individual particles. This ratio was then used to obtain particle mass and density. A mean particle mass for the sample studied was obtained using a direct gravimetric method $[8,13]$. This method involved weighing and counting several thousand coal particles. Finally, the mean mass obtained using the EDB measurement system was validated by comparison with the results of the direct gravimetric method.

In view of the anticipated rapid development of technologies for co-feeding of coal and biomass, a great need exists for the development of a data base on the shape and density distributions of biomass particles for use in combustion models. Detailed property data including surface area, volume, mass, and density distributions for several coal samples are now available $[8,13]$ for use in coal combustion models.

To this end, applying our experimental and analytical capabilities in the particle characterization research $[5,8,10-11,13]$, this project seeks to characterize the shape and mass for biomass particles. Individual biomass particles will be characterized for their external surface area, volume, and drag coefficient/mass ratios. Analysis methods will be employed using shape and drag information to calculate mass and density distributions for these particles. Results of these measurements and analyses will be validated by independent mass measurements using a particle weighing and counting technique.

The specific objectives are:

1) Apply unique measurement systems to characterize external surface area, volume, mass, and density for a statistically significant number of individual biomass particles (20 particles) in the size range of $100-200 \mu \mathrm{m}$.

2) Obtain mean mass per particle of the biomass sample tested in Objective (1) by independent mass measurements of several thousand particles using a particle weighing and counting technique.

Experiments and data analysis are being carried out to meet the project objectives. Mean mass of several thousand biomass particles obtained in Objective (2) will be used to validate the mean mass per particle obtained in Objective (1). Co-firing of biomass and coal has been identified as a promising way of reducing net $\mathrm{CO}_{2}$ emissions with minimum modifications in the existing technologies. The successful accomplishment of the above objectives will provide detailed particle property data required for developing improved combustion kinetic models for technologies involving co-firing of coal and biomass feedstocks.

\section{EXECUTIVE SUMMARY}


In this semi-annual report, the work performed under DOE Grant No. DE-FC26-04NT42130 during the period January 01, 2006 to June 30, 2006, which covers the fourth six months of the project is described and the major accomplishments are highlighted summarizing the most important research results.

Over the next decade there will be a renewed emphasis on co-firing biomass with coal. Cofiring of biomass and coal has been identified as a promising way of reducing net $\mathrm{CO}_{2}$ emissions with minimum modifications in the existing technologies. Coal and biomass particles are irregular in shape. From a combustion perspective, particle sphere assumptions employed in most coal combustion models were found to yield significant errors (20 to 25 percent) in calculated particle volume and associated thermal mass. Even if surface area and volume differences were adequately handled in a heat transfer analysis, large uncertainties still resulted in coal particle temperature response due to particle to particle density variations. Recently, shape and density for coal particles have been characterized and detailed property data including surface area, volume, mass, and density distributions for several coal samples are now available for use in coal combustion models.

This project seeks to characterize the shape and mass for biomass particles. Individual biomass particles will be levitated in an electrodynamic balance (EDB) and their external surface area, volume, and drag coefficient/mass $\left(\mathrm{C}_{\mathrm{d}} / \mathrm{m}\right)$ ratios will be characterized applying highly specialized video based and high-speed diode array imaging systems. Analysis methods will be employed using shape and drag information to calculate mass and density distributions for these particles. Results of these measurements and analyses will be validated by independent mass measurements using a particle weighing and counting technique. Experiments involving counting and weighing of several thousand biomass particles employing a microscope and a sub-milligram balance experimental system will be performed by Morehouse College in Atlanta. Experiments involving imaging systems will be performed by REM Engineering Services, our subcontractor in this project, using the EDB measurement system available at the single particle laboratory, National Energy Technology Laboratory (NETL), Morgantown. Morehouse will analyze the raw data collected in this project including that by REM. The successful accomplishment of the above goals will provide detailed particle property data required for developing improved combustion kinetic models for technologies involving co-firing of coal and biomass feedstocks.

During this reporting period, Morehouse completed obtaining additional mean mass measurements for biomass particles employing the gravimetric technique measurement system that was set up in a previous reporting period. Simultaneously, REM, our subcontractor, has completed obtaining raw data for surface area, volume, and drag coefficient to mass ratio $\left(C_{d} / m\right)$ information for 9 more biomass particles employing the electrodynamic balance (EDB) measurement system that was calibrated before in this project. Results of the mean mass data obtained to date are reported here, and analysis of the raw data collected by REM is in progress. 


\section{EXPERIMENTAL}

Presently, work is in progress to characterize surface area, volume, mass, and density distributions for sized biomass particles. During this reporting period, REM Engineering Services, our subcontractor, has obtained raw data for particle $\mathrm{C}_{\mathrm{d}} / \mathrm{m}$, external surface area, and volume for several more biomass particles. Morehouse has continued and completed mean mass measurements for several thousand more biomass particles using the gravimetric technique that was setup before in this project.

Measurement of Particle $\mathrm{C}_{\mathrm{d}} / \mathrm{m}$, External Surface Area, Volume, Mass, and Density:

Individual biomass particles were levitated in the electrodynamic balance (EDB) and characterized using high-speed optical and electronic instruments. Single particles were backlit with a red He:Ne laser at the side and with a light emitting diode (LED) from the bottom of the balance. The magnified shadow image of the side view was split and projected onto the detector of a CCD video camera imaging system and a high-speed diode array imaging system. The magnified shadow image of the bottom view was projected onto the detector of a second CCD video camera imaging system positioned above the balance. The diode array imaging system was used to characterize particle drag coefficient/mass $\left(\mathrm{C}_{\mathrm{d}} / \mathrm{m}\right)$ ratios. The video-based imaging systems (side and top) were used for shape characterization. The details of the diode array and the video based imaging systems can be obtained elsewhere [13]; only brief discussion is given below.

Particle $\mathrm{C}_{\mathrm{d}} / \mathrm{m}$ ratios were determined based on measurements of particle trajectory in the EDB. Particles were balanced in the EDB and a step change was applied to the EDB endcap voltage, stimulating a dynamic response of the particle from its balance position. The resulting transient motion of the particle was measured using the high-speed diode array imaging system, which provided an analog output indicating particle position along the EDB center axis. A force balance model referred to as the Particle Dynamic Model (PDM) was used to simulate the particle trajectory in the EDB. The only unknown in the force balance was particle $\mathrm{C}_{\mathrm{d}} / \mathrm{m}$, which was determined by matching the model output with the measurements. The details of the $\mathrm{C}_{\mathrm{d}} / \mathrm{m}$ measurement can be obtained elsewhere [11].

Following the approach of Maloney et al. [10], raw data for volumes and external surface areas for 9 individual biomass particles were obtained during this reporting period by rotating particles and recording image data for successive video fields as a function of rotation angle using side view video imaging system. Particles were rotated about the EDB center axis using six directed gas jets equally spaced about the EDB centerplane. Rotation rates were established in the range of 10 to 15 revolutions per minute and were determined with the aid of the top view video camera.

Mean Mass Measurements by Gravimetric Technique:

Additional mean particle mass for the biomass sample tested was obtained using the direct gravimetric measurement system that was set up before in this project. This involved weighing and counting several thousand biomass particles. A paper boat was made with a grid paper and its empty weight measured using a sub- milligram balance (uncertainty $\pm 10 \mu \mathrm{g}$ ). Several thousand biomass particles were dispersed on the grid surface and the weight of the particles plus the boat was 
measured. The particles were then counted under a microscope. The experiment was repeated several times to obtain a statistically significant mean mass value of the sample studied.

\section{RESULTS AND DISCUSSION}

Preliminary Results of Shape and Mass Measurements for Biomass Particles:

To date REM has collected raw data for a total of 25 biomass particles thus completed meeting the proposed target number of particles as planned in this project. Analysis of the raw data for surface area, volume, mass, and density for 16 particles collected in the past was completed before and preliminary results were reported in the previous reporting period. Analysis of the raw data for the remaining 9 particles collected during this reporting period is in progress. Surface areas and volumes are being calculated by summing the surface and volume elements swept out during rotation from one video field to the next. The observed surface area and volume will be used to estimate particle drag coefficient by applying Brenner's approach [12] for deformed spheres. The particle mass will then be separated from the $\mathrm{C}_{\mathrm{d}} / \mathrm{m}$ ratio. From the mass and volume, the particle density will be determined. Complete details of the video imaging system and the experimental determination of particle 3-D surface area, volume, mass, and density can be obtained elsewhere [8].

Results of the direct gravimetric method:

Weighing and counting of 23,443 biomass particles during the previous reporting periods yielded a mean mass per particle of $1.962 \times 10^{-7} \mathrm{~g}$. Additional 8,690 biomass particles from the same sample were weighed and counted in this reporting period. To date 32,133 particles were weighed and counted and the mean mass per particle for a total of 32,133 biomass particles was found to be $1.823 \times 10^{-7} \mathrm{~g}$.

\section{Plans for the next Reporting Period}

Analysis of the raw data for 9 biomass particles collected by REM is expected to be completed by the end of the next reporting period. Results of the shape, mass, and density information for the 25 biomass particles tested will be presented in the next reporting period. Shape, density, and mass correlations for coal/biomass blends will be developed in the next reporting period with previously published information obtained from similar research for coal particles. These correlations will be useful in predicting the burning rate of coal/biomass blends in co-firing combustors.

\section{Students Supported under this Research}

Michael D. Young, an undergraduate student, Morehouse College was supported in the fall semester 2004. George Weirko-Brobby, a second undergraduate student from Morehouse was supported in the spring semester 2005. George graduated May, 2005. Gautam Saha, a graduate student has been supported in the summer of 2005. Presently, Mallikah Byars, an undergraduate student is being supported in this grant.

\section{Outcome to-date}

Several experiments and theoretical analyses were conducted in this project. These activities 
resulted in several reports, and conference presentations and are listed below.

1. Sampath, R., Dixon, R. M., Young, M. D., Weirko-Brobby, G., Surface Area, Volume, Mass, and Density Distributions for Sized Biomass Particles, 2005 University Coal Research / Historically Black Colleges and Universities and other Minority Institutions Contractors Review Meeting, sponsored by NETL/U.S. DOE, June 7-8, 2005, Pittsburgh, PA.

2. Sampath, R., Brown, C. S., and Monazam, E. R., Surface Area, Volume, Mass, and Density Distributions for Sized Biomass Particles, First Semi-Annual Progress Report submitted to NETL/DOE, Pittsburgh, January 2005.

3. Sampath, R., Brown, C. S., and Monazam, E. R., Surface Area, Volume, Mass, and Density Distributions for Sized Biomass Particles, Second Semi-Annual Progress Report submitted to NETL/DOE, Pittsburgh, July 2005.

4. Sampath, R., Brown, C. S., and Monazam, E. R., Surface Area, Volume, Mass, and Density Distributions for Sized Biomass Particles, Third Semi-Annual Progress Report submitted to NETL/DOE, Pittsburgh, January 2006.

5. Brown, C. S., Sampath, R., Byars, M., Saha, G., and Monazam, E. R., Surface Area, Volume, Mass, and Density Distributions for Sized Biomass Particles, 2006 University Coal Research / Historically Black Colleges and Universities and other Minority Institutions Contractors Review Meeting, sponsored by NETL/U.S. DOE, June 6-7, 2006, Pittsburgh, PA.

\section{CONCLUSION}

The project is progressing well. To date, supply requests were processed and supplies including biomass test particles (hardwood sawdust AI14546) in the size range of 100-200 microns were obtained from a co-firing pilot plant research facility owned by Southern Company, Birmingham, AL. Setting up of the of the gravimetric measurement system in the Heat Transfer Laboratory, Department of Physics and Dual Degree Engineering, Morehouse College has been completed by Morehouse, and mean mass measurements were completed as planned. Also completed was the setting up of the EDB measurement system to characterize shape and mass for individual biomass particles by our subcontractor, REM. Calibration of the video based imaging systems and diode-array imaging system using known sizes of polystyrene particles were completed. Collection of raw data for shape and density information for 25 biomass particles have been completed by REM. Results for mean mass measurements using the gravimetric measurement system are reported here, and analysis of the raw data for shape and density information is in progress.

\section{FUTURE WORK}

Setting up, calibration, testing of the measurement systems with actual biomass particles 
have been completed to date. Also data collection using these measurement systems have just been completed, and preliminary results are reported in this reporting period. This amounts to more than $75 \%$ of the proposed project work completed to date. Remaining $25 \%$ of the project work including completion of data analysis, development of correlations for coal/biomass blends, and final reporting with recommendations to additional research is anticipated to be completed in the third performance year of the project.

\section{ACKNOWLEDGMENTS}

This work is supported under NETL/DOE Grant No. DE-FC26-04NT42130. Technical discussions provided by Daniel J. Maloney PhD, and Charles E. Miller P.E. of National Energy Technology Laboratory, Morgantown, are gratefully acknowledged.

\section{REFERENCES}

1. Goldstein, I. S., ACS Symposium Series No. 476, American Chemical Society, Washington, DC, pp. 332338 (1992).

2. Goldstein, I. S., in Organic Chemicals from Biomass (Boca Raton, Ed.), CRC Press (1981).

3. Rosin, P. O., The influence of particle size in processes of fuel technology, Trans. Inst. Chem. Engrs., 15: 167 (1937).

4. Heywood, H., The scope of particle size analysis and standardization, Trans. Inst. Chem. Eng. 25:14 (1947).

5. Maloney, D. J., E. R. Monazam, S. W. Woodruff, and L. O. Lawson., Measurement and analysis of temperature histories and size changes for single carbon and coal particles during the early stages of heating and devolatilization, 1991. Combustion and Flame 84: 210-220.

6. Solomon, P. R., M. A. Serio, R. M. Carangelo, and J. R. Markham., Very rapid coal pyrolysis, 1986. Fuel 65, 182.

7. Tichenor, D. A., Mitchell, R. E., Hencken, K. R., and Niksa, S., Simultaneous in situ measurement of the size, temperature and velocity of particles in a combustion environment, Twentieth Symposium (International) on Combustion, p. 1213, The Combustion Institute, 1985.

8. Monazam, E. R. and D. J. Maloney, Characterization of mass and density distributions of sized coal fractions, Combustion and Flame, 99, 733-741, 1994.

9. Hurt, R. H. and Mitchell, R. E., On the combustion kinetics of heterogeneous char particle populations, Twenty-Fourth Symposium (International) on Combustion, p. 1233, The Combustion Institute, 1992.

10. Maloney, D. J., Lawson, L. O., Fasching, G. E., and Monazam, E. R., A novel approach for determining external surface area and volume of irregularly shaped particles, Aerosol Sci. Technol. (1994).

11. Maloney, D. J., Lawson, L. O., Fasching, G. E., and Monazam, E. R., Measurement and dynamic simulation of particle trajectories in an electrodynamic balance: characterization of particle drag coefficient/mass ratios, Rev. Sci. Instrum., 66, 6, 3615-3622, 1995.

12. Brenner, H., The Stokes resistance of a slightly deformed sphere, Chem. Eng. Sci. 19:519 
(1964).

13. Sampath, R. (1994), Measurement and Prediction of Temperature Histories for Single Coal Particles Prior to and During Devolatilization, Ph.D. thesis, Department of Chemical Engineering, West Virginia University. 